\title{
ESTUDO COMPARATIVO DA SECAGEM DA POLPA DE GRAVIOLA EM CAMADA DE ESPUMA, LEITO DE JORRO E EM SECADOR SPRAY
}

\author{
J. S. de OLIVEIRA ${ }^{1}$, T. M. DELMIRO ${ }^{1}$, A. K.T. MACHADO ${ }^{1}$, C. E. M. R. GURGEL ${ }^{1}$, M. \\ de F. D. de MEDEIROS ${ }^{1}$
}

${ }^{1}$ Universidade Federal do Rio Grande do Norte, Departamento de Engenharia Química E-mail para contato: joysoliveira@outlook.com

\begin{abstract}
RESUMO - Neste trabalho foram testadas e comparadas diferentes técnicas de secagem da polpa de graviola com adição de adjuvantes, em leito de jorro, camada de espuma e em secador spray, sendo avaliados o desempenho dos processos e as características físico-químicas dos pós e o dos produtos reconstituídos por reidratação dos pós. Os resultados indicam que os três métodos são eficazes para a secagem da polpa de graviola com adjuvantes, apresentando desempenho satisfatório, produção de pós com características físico-químicas similares e com valores de umidade e atividade de água adequados para conservação e armazenamento.
\end{abstract}

\section{INTRODUÇÃO}

O processo de secagem em camada de espuma (foam-mat) é um método de desidratação no qual alimentos líquidos e semilíquidos são transformados em uma espuma estável através da adição de agentes químicos com propriedades emulsificantes e espessantes (Soares, 2001). Como alternativa à secagem em tambor essa técnica ocorre em um tempo relativamente curto, devido a maior área superficial de troca térmica da amostra.

A secagem no leito de jorro com partículas inertes é uma alternativa de baixo custo à secagem por nebulização (spray dryer) e vem se destacando na secagem de pastas e suspensões. Os pós produzidos apresentam características bastante semelhantes, porém a secagem de leito de jorro tem como desvantagem os problemas com ampliação de escala.

A secagem por nebulização (spray dryer) é uma das técnicas utilizadas no processamento industrial do leite em pó. Muito utilizada na secagem de alimentos líquidos ou pastosos, essa técnica consiste na pulverização da amostra dentro da câmara de secagem que entra em contato com o ar quente e de forma instantânea evapora a água presente nas gotas. Segundo Schuck (2009), a diminuição dos danos térmicos ao produto se deve ao fato de que a formação das pequenas gotículas das amostras e a grande área superficial resultante dessas proporciona uma rápida evaporação da água a uma temperatura relativamente baixa.

A graviola é uma planta originária da América Central e ao Norte da América do Sul (Sobrinho, 2010). Como mostrado na figura 1, a graviola é uma fruta com casca de coloração verde e espinhosa, polpa em formato de gomos de cor branca e muito aromática. Na medicina 
popular, essa fruta é utilizada com fins medicinais para tratamento de doenças inflamatórias, como úlceras, e estudos recentes buscam provar seus efeitos em doenças como câncer. Apesar da escassez de dados recentes sobre a cultura da gravioleira no Brasil, sabe-se que seu cultivo tem crescido bastante nos últimos anos (Lemos, 2014). Tendo em vista a alta perecibilidade dessa fruta após a colheita e o aumento da produção, o estudo das técnicas de secagem da polpa de graviola se fazem necessários para a conservação desse produto e possibilidade de transporte para áreas distantes das regiões de cultivo.

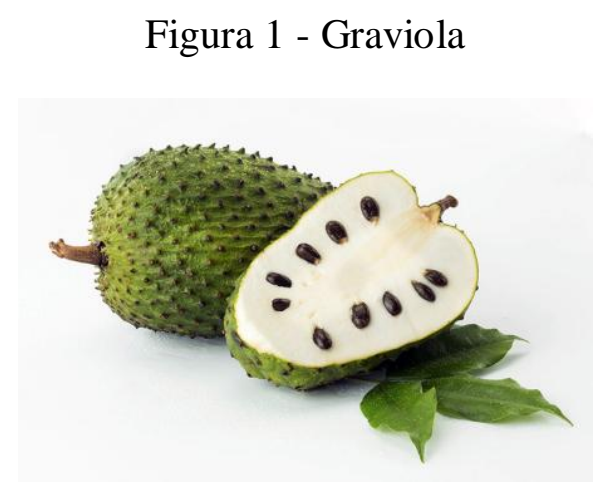

Este trabalho tem como objetivo analisar e comparar o desempenho dos processos de secagem em leito de jorro, camada de espuma e em spray da polpa da graviola com adjuvantes, avaliando as características físico-químicas dos produtos em pó e ao desempenho de cada secador em relação a produção de pó e capacidade de processamento.

\section{METODOLOGIA}

\subsection{Secagem em leito de jorro}

Para a secagem em leito de jorro, foi adicionado o leite integral à polpa de graviola nas proporções de $30 \%$ e $50 \%$ em relação à massa de polpa. Na formulação das amostras, as polpas foram descongeladas e pesadas. A partir dessa massa foi calculada a quantidade de leite necessária para a mistura, homogeneizada em liquidificador doméstico. Os ensaios foram realizados em secador com alimentação atomizada através de bico injetor duplo fluido, velocidade no ar da coluna igual a $1,3 \mathrm{~m} / \mathrm{s}$, vazão de alimentação da polpa de $8 \mathrm{ml} / \mathrm{min}$, variando as temperaturas de entrada do ar entre 70 e $90^{\circ} \mathrm{C}$ e utilizando um leito de $2500 \mathrm{~g}$ de partículas inertes de polietileno de alta densidade

\subsection{Secagem em camada de espuma (foam-mat)}

O método de secagem em camada de espuma foi realizado utilizando a polpa de graviola, o estabilizante liga neutra, o emulsificante e o leite fluido integral. Nas formulações, foram adicionados à polpa de graviola, os percentuais de $1 \%$ de liga neutra, $1 \%$ de emulsificante, $20 \%$ e $40 \%$ de leite. No procedimento, inicialmente, as polpas foram descongeladas e as massas dos demais aditivos e do leite foram pesadas separadamente. Logo após, as amostras foram homogeneizadas em batedeira durante 30 minutos para a formação da espuma. Essas espumas foram transferidas para as placas com espessuras variáveis de 0,3, 0,45 e $0,6 \mathrm{~cm}$ e submetidas à secagem em estufa com circulação de ar. As temperaturas utilizadas variaram entre os valores de 50,60 e $70^{\circ} \mathrm{C}$. 


\subsection{Secagem por nebulização (spray dryer)}

Utilizou-se como base $100 \mathrm{~g}$ de polpa de graviola para preparação de todas as formulações. Os adjuvantes usados foram leite integral e proteína do soro do leite (whey). Foram preparadas duas formulações, na primeira misturando $6 \%$ da proteína a polpa de graviola e na segunda adicionando $4 \%$ de proteína e $33,3 \%$ de leite à polpa de graviola. As misturas foram preparadas com as polpas descongeladas, realizando-se a pesagem das massas de todos os componentes, e homogeneizando as misturas em liquidificador doméstico. Os ensaios foram realizados utilizando um secador por nebulização "mini spray dryer", modelo MSD 1.0 fabricante LABMAQ DO BRASIL LMTD. Todos os experimentos foram realizados a uma temperatura fixa de $120^{\circ} \mathrm{C}$, vazão de ar comprimido de $35 \mathrm{~L} / \mathrm{min}$, vazão de ar soprado de $1,65 \mathrm{~m}^{3} / \mathrm{min}$, com um bico de atomização de $1,2 \mathrm{~mm}$ de diâmetro e vazão de alimentação da mistura de $0,45 \mathrm{~L} / \mathrm{h}$. O tempo de secagem das amostras variou entre 20 e 25 minutos, desconsiderando o tempo gasto na montagem do equipamento.

\subsection{Formulações}

O resumo das formulações das misturas de polpa de graviola com adjuvantes é mostrado na tabela 1 .

Tabela 1 - Formulações das misturas

\begin{tabular}{ccccccccc}
\hline & \multicolumn{3}{c}{ Leito de Jorro } & \multicolumn{3}{c}{ Foam-mat } & \multicolumn{2}{c}{ Spray Dryer } \\
\hline Ensaio & L1 & L2 & L3 & F1 & F2 & F3 & S1 & S2 \\
\hline Leite & $30 \%$ & $50 \%$ & $50 \%$ & $20 \%$ & $40 \%$ & $40 \%$ & - & $33,3 \%$ \\
Emustab & - & - & - & $1 \%$ & $1 \%$ & $1 \%$ & - & - \\
Liga Neutra & - & - & - & $1 \%$ & $1 \%$ & $1 \%$ & - & - \\
Whey & - & - & - & - & - & - & $6 \%$ & $4 \%$ \\
Temperatura & $70^{\circ} \mathrm{C}$ & $70^{\circ} \mathrm{C}$ & $90^{\circ} \mathrm{C}$ & $60^{\circ} \mathrm{C}$ & $50^{\circ} \mathrm{C}$ & $70^{\circ} \mathrm{C}$ & $120^{\circ} \mathrm{C}$ & $120^{\circ} \mathrm{C}$ \\
\hline
\end{tabular}

\subsection{Análises físico-químicas}

As análises descritas no presente trabalho foram realizadas no Laboratório de Tecnologia de Alimentos do Departamento de Engenharia Química da UFRN.

As medidas de $\mathrm{pH}$ foram realizadas utilizando potenciômetro TECNAL, Modelo: Tec5 e dos sólidos solúveis (SST) em ${ }^{\circ}$ Brix utilizando o refratômetro digital, ATAGO, SMART1. As umidades das misturas determinadas mediante secagem em estufa de circulação com ar (TECNAL TE-394/I, Brasil) a $70^{\circ} \mathrm{C}$ por 24 horas e a dos pós utilizando-se uma balança de infravermelho (METTLER TOLEDO, LJ16). A temperatura da balança foi ajustada para $105^{\circ} \mathrm{C}$ e o tempo para 30 minutos. As atividades de água dos pós (aW) medidas em analisador de atividade de água do tipo AQUALAB (SERIE 3TE, Brasil).

A análise da acidez total titulável (ATT) foi realizada conforme as Normas Analíticas do Instituto Adolfo Lutz (1985) através da titulação com solução de hidróxido de sódio a 0,1 $\mathrm{N}$ de amostras de $0,5 \mathrm{~g}$ para os pós ou $0,5 \mathrm{ml}$ para a polpa e misturas, diluídas em $25 \mathrm{ml}$ de água destilada. Como indicador de $\mathrm{pH}$ foi inserido de 3 a 4 gotas de fenolftaleína. 
Para determinar a solubilidade dos pós foi utilizado o método descrito por Eastman \& Moore (1984) modificado por Cano-Chauca et. al., (2005), mediante preparação de solução dos pós em água com agitação por 5 minutos e posterior centrifugação. Parte do sobrenadante é submetida à secagem em estufa durante 24 horas. A solubilidade é calculada através da diferença de peso inicial e final da amostra em relação ao peso inicial, expressa em \%.

A reconstituição da mistura do pó em água foi realizada pela reidratação do pó, com determinação do seu tempo de reconstituição, segundo o método descrito por Kachan (1988). Adicionou-se água destilada ao pó em quantidade suficiente para obter-se uma pasta com $12^{\circ}$ Brix (teor característico de sólidos solúveis totais da mistura de frutas in natura). A mistura foi submetida à agitação a 200rpm, com acompanhamento visual, em intervalos de 30 segundos, até que se observasse o desaparecimento do pó aglomerado.

\section{RESULTADOS E DISCUSSÃO}

Na tabela 2 são exibidos os dados relativos à caracterização da polpa de graviola e das misturas processadas pelos diferentes métodos de secagem. Conforme se observa a adição do leite proporciona uma diminuição no teor de sólidos solúveis e acidez e aumento do $\mathrm{pH}$ das misturas processadas no leito de jorro e pelo método da camada de espuma. O comportamento inverso para as mesmas variáveis nas misturas processadas no spray pode ser explicado pela adição da proteína do soro do leite como adjuvante da secagem.

Tabela 2 - Análises físico-químicas das polpas antes do processamento

\begin{tabular}{cccccccc}
\hline & & \multicolumn{2}{c}{ Leite de Jorro } & \multicolumn{2}{c}{ Camada de } & \multicolumn{2}{c}{ Espuma } \\
\hline Ensaio & Graviola & L1 & L2 e & F1 & F2 e & S1 & S2 \\
SST ( ${ }^{\circ}$ Brix $)$ & 12,66 & 12,89 & 9,69 & 10,76 & 10,23 & 17,67 & 16,39 \\
Acidez $(\%)$ & 1,46 & 0,53 & 0,46 & 0,53 & 0,48 & 1,99 & 1,38 \\
pH (\%) & 3,61 & 4,17 & 4,47 & 4,02 & 4,38 & 3,31 & 3,01 \\
\hline
\end{tabular}

Na tabela 3 são mostrados os dados relativos à caracterização dos pós obtidos pelos diferentes processos. Pode-se observar os menores valores de umidade para os pós em secador spray e em camada de espuma. Para o leito de jorro é possível perceber que o aumento da temperatura e o aumento do percentual de leite provocaram a diminuição dos valores de umidade. Observa-se que os percentuais de acidez determinados para os pós no leito de jorro e em camada de espuma variaram entre 3,22 e 4,46\%, porém para os pós obtidos na secagem no spray os valores foram mais elevados, o que corrobora com os resultados relativos a caracterização das misturas e atribuída a adição da proteína do soro do leite. A solubilidade dos pós variou entre 64,18 e $81,88 \%$, sendo o maior valor observado no pó obtido na secagem da polpa de graviola sem adição de leite no spray. Para o leito de jorro e em camada de espuma, as maiores solubilidades foram alcançadas nos ensaios realizados com menor percentual de leite adicionado. Estes resultados demonstram que a adição do leite provoca a diminuição na solubilidade dos pós. De uma forma geral os três processos estudados levaram a produção de pós com teores de umidade e atividade de água baixas e adequadas para conservação e armazenamento e solubilidade satisfatória. 
Tabela 3 - Caracterização físico-química dos pós

\begin{tabular}{ccccccccc}
\hline & \multicolumn{3}{c}{ Leito de Jorro } & \multicolumn{4}{c}{ Camada de Espuma } & \multicolumn{2}{c}{ Spray } \\
\hline Ensaio & L1 & L2 & L3 & F1 & F2 & F3 & S1 & S2 \\
Umidade (\%) & 7,17 & 5,53 & 4,41 & 5,5 & 4,24 & 2,8 & 4,2 & 4,1 \\
Atividade (aW) & 0,375 & 0,331 & 0,274 & 0,304 & 0,311 & 0,28 & 0,22 & 0,17 \\
Acidez (\%) & 4,46 & 3,22 & 3,81 & 4,32 & 3,41 & 3,43 & 8,73 & 7,11 \\
Solubilidade & 70,20 & 64,18 & 66,52 & 79,31 & 69,81 & 72,66 & 81,88 & 73,43 \\
$(\%)$ & & & & & & & & \\
\hline
\end{tabular}

Comparando-se os resultados relativos à caracterização físico-química das misturas antes de serem processadas (tabela 2) e reconstituídas (tabela 4) pode-se observar que para os três métodos de secagem as características físico-químicas das misturas reconstituídas não sofreram variações relevantes devido ao processamento. Ainda na tabela 4 pode-se observar que os pós obtidos no leito de jorro apresentaram menores tempos de reconstituição enquanto para os pós obtidos no spray o tempo de reconstituição em água foi bastante elevado. $\mathrm{O}$ menor tempo de reconstituição para os pós produzidos no leito de jorro pode ser atribuído a maior granulometria destes, comparativamente a fina granulometria observada nos pós obtidos no secador spray.

Tabela 4 - Caracterização físico-química das misturas reconstituídas

\begin{tabular}{ccccccccc}
\hline & \multicolumn{3}{c}{ Leito de Jorro } & \multicolumn{3}{c}{ Camada de Espuma } & \multicolumn{2}{c}{ Spray } \\
\hline Ensaio & L1 & L2 & L3 & F1 & F2 & F3 & S1 & S2 \\
Sólidos Solúveis (\%) & 13,00 & 12,59 & 10,91 & 10,67 & 10,83 & 9,86 & 18,66 & 16,22 \\
pH (\%) & 4,04 & 4,48 & 4,43 & 3,90 & 4,15 & 4,38 & 3,35 & 3,53 \\
Acidez (\%) & 0,775 & 0,496 & 0,543 & 0,631 & 0,527 & 0,465 & 1,89 & 1,26 \\
$\begin{array}{c}\text { Tempo de } \\
\text { reconstituição (s) }\end{array}$ & 120 & 80 & 90 & 150 & 130 & 160 & 196 & 211 \\
\hline
\end{tabular}

Na tabela 5 são mostrados os resultados referentes à capacidade de processamento e produção de pó pelos três métodos de secagem. Pode-se perceber que o menor tempo de processamento foi alcançado na secagem no secador spray e o maior tempo na secagem em camada de espuma. Uma das vantagens da secagem em spray relatada na literatura é a rapidez do processo, logo esse resultado condiz com o esperado. Ao analisar a razão de massa processada pelo tempo de secagem é possível perceber que os ensaios L2 e S2 apresentam valores muito próximos, indicando que a otimização dos parâmetros de secagem no leito de jorro leva a um desempenho energético compatível com a secagem no spray. Em termos de produção o rendimento do jorro supera ao do secador spray. Com relação ao elevado rendimento na produção de pó pelo processo de secagem em camada de espuma, este é justificado pelo método ser conservativo em relação aos sólidos, pois as perdas se referem apenas ao material aderido as placas após a raspagem das mesmas. Contrariamente ao processo em camada de espuma, no jorro e no secador spray ocorrem perdas por arraste dos pós. 
Tabela 5 - Análise de desempenho dos métodos de secagem

\begin{tabular}{ccccccccc}
\hline & \multicolumn{3}{c}{ Leito de Jorro } & \multicolumn{3}{c}{ Foam-mat } & \multicolumn{3}{c}{ Spray Dryer } \\
\hline Ensaio & L1 & L2 & L3 & F1 & F2 & F3 & S1 & S2 \\
Massa processada (g) & 227,3 & 277,92 & 249,36 & 96,12 & 100,25 & 81,92 & 107,81 & 164,24 \\
Tempo de secagem (min) & 84 & 60 & 84 & 130 & 280 & 110 & 25 & 35 \\
Massa processada/tempo de & 2,70 & 4,632 & 2,97 & 0,73 & 0,35 & 0,74 & 4,28 & 4,69 \\
secagem (g/min) & & & & & & 69 & 25,70 & 32,87 \\
Eficiência de produção (\%) & 29,89 & 42,65 & 36,28 & 64 & 65 & 69 & 4,8 \\
Umidade do pó (\%) & 7,17 & 5,53 & 4,41 & 5,56 & 4,24 & 2,80 & 4,2 & 4,1 \\
\hline
\end{tabular}

\section{CONCLUSÃO}

De acordo com os resultados apresentados e discutidos, pode-se concluir que os produtos obtidos pela secagem da polpa de graviola, pelos três métodos de secagem estudados, não apresentaram variações importantes nas características físico-químicas em relação às misturas não processadas, o que demostra o baixo impacto do processo sobre o produto. A secagem no spray e no jorro apresentaram desempenhos compatíveis em relação a capacidade de processamento, todavia em relação a produção o jorro apresentou maior rendimento. A secagem em camada de espuma, apesar da pequena capacidade de processamento, apresenta elevado rendimento. Por se tratar de uma secagem mais simples e de baixo custo, este método apesar de limitado em relação à capacidade de processamento é viável para a produção em pequena escala. Os pós obtidos pelos diferentes processos apresentaram valores de umidade e atividade de água adequados para conservação e armazenamento.

\section{REFERÊNCIAS}

BORGES, K.C.; BEZERRA, M. D. F.; ROCHA, M. P.; SILVA, E. S. D.; FUJITA A.; GENOVESE, M. I.; PINTO CORREIA, R. T.; Fresh and Spray Dried Pitanga (Eugenia uniflora) and Jambolan (Syzygium cumini) Pulps are Natural Sources of Bioactive Compounds with Functional Attributes. J. Prob. Health, v.4, n. 2, p 2-8, 2016.

LEMOS, E. E. P. de. A produção de anonáceas no Brasil. Rev. Bras. Frutic. Jaboticabal, v. 36, p. 77-85, 2014.

SCHUCK, P. Spray drying of dairy products: state of the art. Lait,Rennes, v. 82, n.4, p. 375 382, 2002.

SOARES, E. C.; OLIVEIRA, G. S. F. de; MAIA, G. A.; MONTEIRO, J. C. S.; SILVA Jr, A.; S. FILHO, M. de S. de. Desidratação da polpa de acerola (Malpighia emarginata D. C.) pelo processo foam-mat. Food Sci. Technol (Campinas), v. 21, n.2, 2001.

SOBRINHO R. B., Potencial de Exploração de Anonaceas no Nordeste do Brasil, Embrapa Agroindústria Tropical, Fortaleza, 2010.

SOUZA, J. S. de. Secagem de misturas de polpa de frutas tropicais em leito de jorro. 2009. 178 f. Tese (Doutorado em Pesquisa e Desenvolvimento de Tecnologias Regionais) Universidade Federal do Rio Grande do Norte, Natal, 2009. 